\title{
GEOMETRIC CALIBRATION AND RADIOMETRIC CORRECTION OF THE MAIA MULTISPECTRAL CAMERA
}

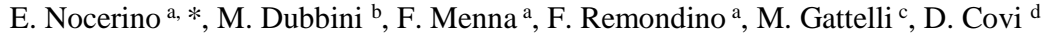 \\ a 3D Optical Metrology (3DOM) unit, Bruno Kessler Foundation (FBK), Trento, Italy \\ (nocerino, fmenna, remondino)@fbk.eu, http://3dom.fbk.eu \\ b DiSCi, sec. Geography, University of Bologna, via Guerrazzi 20, 40125 Bologna, Italy - marco.dubbini@ unibo.it \\ ${ }^{c}$ SAL Engineering srl, Russi, Italy - mgattelli@ salengineering.it, http://www.salengineering.it \\ ${ }^{\mathrm{d}}$ Eoptis srl, Trento, Italy - daniele.covi@eoptis.com, https://www.eoptis.com
}

\section{Commission II, WG II/7}

KEY WORDS: Multispectral, Geometrical Calibration, Radiometric Calibration, MAIA

\begin{abstract}
:
Multispectral imaging is a widely used remote sensing technique, whose applications range from agriculture to environmental monitoring, from food quality check to cultural heritage diagnostic. A variety of multispectral imaging sensors are available on the market, many of them designed to be mounted on different platform, especially small drones. This work focuses on the geometric and radiometric characterization of a brand-new, lightweight, low-cost multispectral camera, called MAIA. The MAIA camera is equipped with nine sensors, allowing for the acquisition of images in the visible and near infrared parts of the electromagnetic spectrum. Two versions are available, characterised by different set of band-pass filters, inspired by the sensors mounted on the WorlView- 2 and Sentinel2 satellites, respectively. The camera details and the developed procedures for the geometric calibrations and radiometric correction are presented in the paper.
\end{abstract}

\section{INTRODUCTION}

Multispectral imaging is a branch of remote sensing which entails the acquisition of images in specific wavelengths, not only in the visible part of the electromagnetic spectrum, but encompassing a wide range of spectral bands, from violet to infrared. This technology exploits the properties of different materials and objects in reflecting, scattering, absorbing and emitting electromagnetic radiation in a characteristic way, defined as spectral signature or spectrum (Shaw and Burke, 2003). Such propriety is exploited in multispectral imaging to identify and differentiate diverse subjects in the acquired scene.

Historically, spectral imaging arises in the satellite domain, with the launch of the first Television Infrared Observation Satellite TIROS (Shaw and Burke, 2003) back to the 1960s.

Since then, advances in the manufacturing of sensing components, as well as improvements in processing algorithms, has allowed the miniaturization of the imaging sensors and the widening of applications. Nowadays, thanks to low weights and high signal-to-noise ratios, multispectral imaging sensors can be transported by different type of platforms and applied in various fields. They range from agriculture (vegetative index mapping, water supply planning, optimize pesticide use, fertilization tuning, yield estimation, health condition monitoring, early detection of disease, etc.) (Berni et al., 2009; Candiago et al., 2015; Mulla et al., 2013) to environmental monitoring (surface geology survey, spill of pollutant, hazardous substances, biomass mapping, etc.) (Adam et al., 2010; Ahamed et al., 2011; Leifer et al., 2012; Zang et al., 2012), industry (remote chemical imaging, large industrial plant monitoring, food quality assessment, etc.) (Panagou et al., 2014) and cultural heritage (Liang, 2012; Remondino et al., 2011).

\subsection{Structure of the paper}

The paper aims to present the geometric and radiometric characterization of the brand-new multispectral MAIA camera, available in two versions (Table 1, Figure 2) characterised by different band-pass filters. The main features of the camera are first introduced. Then, the developed approach for its geometric calibration, through the design of an ad-hoc calibration facility, is presented. The radiometric adjustment methods are then described, and the main outcomes and future opportunities are provided in the conclusions.
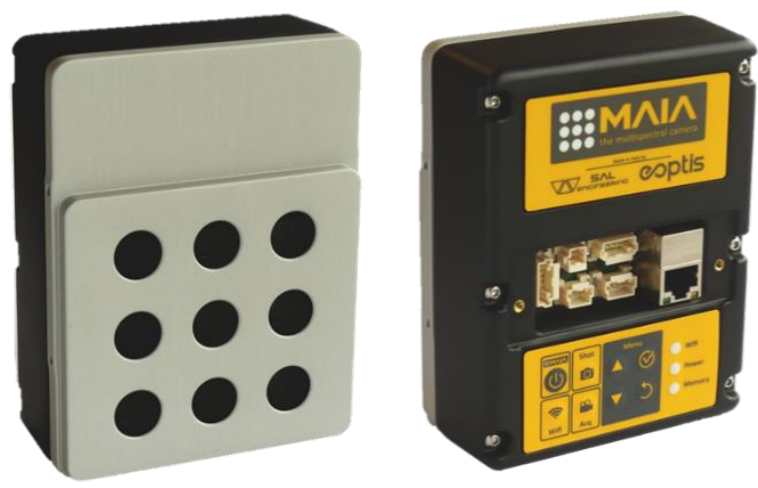

Figure 1. The MAIA multispectral camera (http://www.spectralcam.com).

\footnotetext{
* Corresponding author
} 


\section{THE MAIA MULTISPECTRAL CAMERA}

MAIA (Figure 1) is a multispectral camera, equipped with different sensors (1.2 Mpixel resolution) that allow the simultaneous acquisition of images at various wavelengths in the visible (VIS) and near infrared (NIR) regions. It is mainly designed to be used on UAV platforms, but it may be used also on aircrafts or for terrestrial acquisitions.

\subsection{The two MAIA multispectral versions}

The MAIA camera is available in two versions: the first one has one RGB sensor and eight monochrome sensors, whereas the
MAIA/S2 is equipped with nine monochrome sensors (Table 1, Figure 2). Both cameras are available for analysis of the VIS-NIR spectrum from 390 to $950 \mathrm{~nm}$, operating with a frame rate of up $6 \mathrm{~Hz}$ per sensor (Dubbini et al., 2017). The imaging sensors dimensions are $3.6 \times 4.8 \mathrm{~mm}$, with a $3.75 \mu \mathrm{m}$ pixel size. Each of the eight (or nine for MAIA/S2) sensors is provided with a bandpass filter. The eight band-pass filters installed in the MAIA camera have the same central and width band of sensors mounted on the WorlView-2 (DigitalGlobe, 2009), while the nine bandpass filters installed in MAIA/S2 camera have the same central and width band (from band "1" to band "8a") of sensors mounted on Sentinel2 (ESA, 2012).

\begin{tabular}{|c|c|c|c|c|c|c|}
\hline & \multicolumn{3}{|c|}{ MAIA } & \multicolumn{2}{c|}{ MAIA/S2 } \\
\hline Band & CWL (nm) & FWHM (nm) & Colour & CWL (nm) & FWHM (nm) & Colour \\
\hline $\boldsymbol{b 1}$ & 422.5 & 55 & Violet & 443 & 20 & Violet \\
\hline $\boldsymbol{b} \mathbf{2}$ & 487.5 & 65 & Blue & 490 & 65 & Blue \\
\hline $\boldsymbol{b 3}$ & 550 & 50 & Green & 560 & 35 & Green \\
\hline $\boldsymbol{b 4}$ & 602.5 & 45 & Orange & 665 & 30 & Red \\
\hline $\boldsymbol{b 5}$ & 660 & 60 & Red & 705 & 15 & Red Edge 1 \\
\hline $\boldsymbol{b 6}$ & 725 & 40 & Red Edge & 740 & 15 & Red Edge 2 \\
\hline $\boldsymbol{b} 7$ & 785 & 70 & NIR 1 & 783 & 20 & NIR 1 \\
\hline $\boldsymbol{b 8}$ & 887.5 & 125 & NIR 2 & 842 & 115 & NIR 2 \\
\hline $\boldsymbol{b} 9$ & - & - & RGB & 865 & 20 & NIR 3 \\
\hline
\end{tabular}

Table 1. Optical bands of the two MAIA camera models, characterised by the central wavelength (CWL) and the full width at half maximum (FWHM).
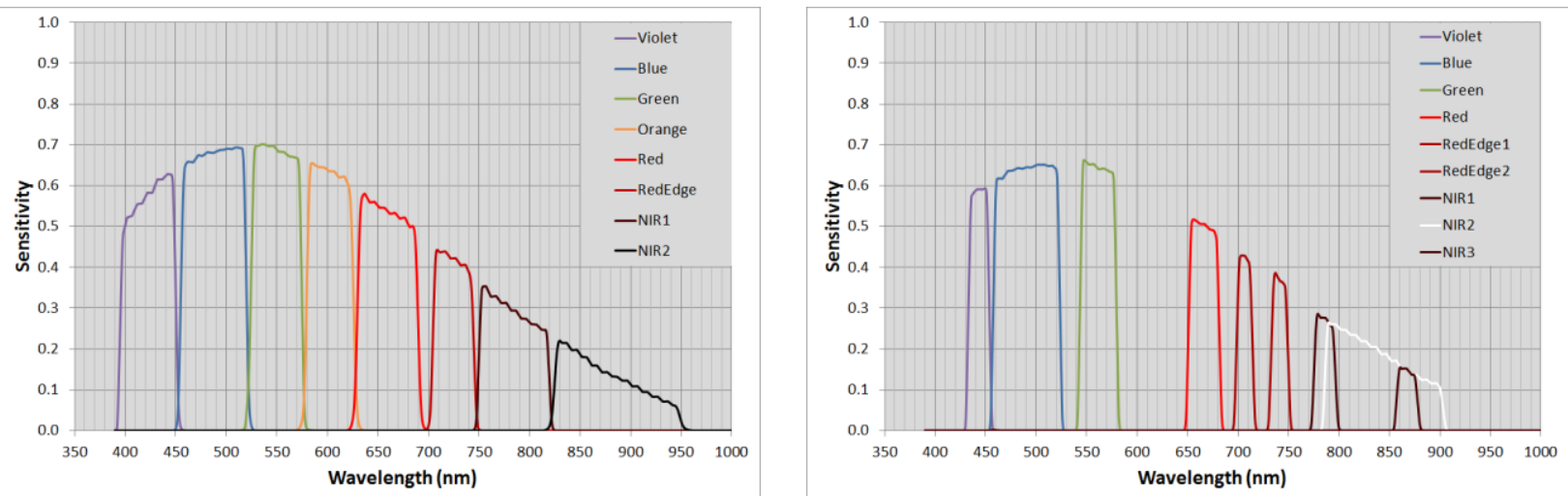

Figure 2. Sensitivity of the optical bands of MAIA (a) and MAIA/S2 (b) cameras. The sensitivities are the products of the quantum efficiency of the sensors and the transmittance of the filters.

a)

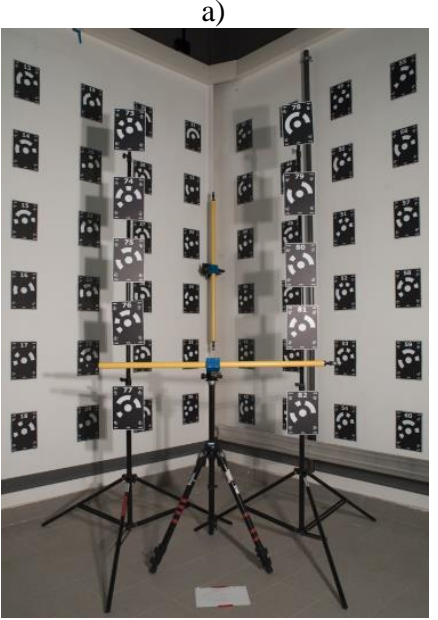

b)

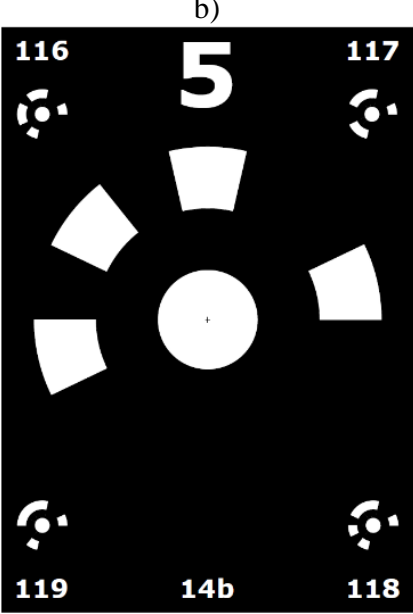

c)

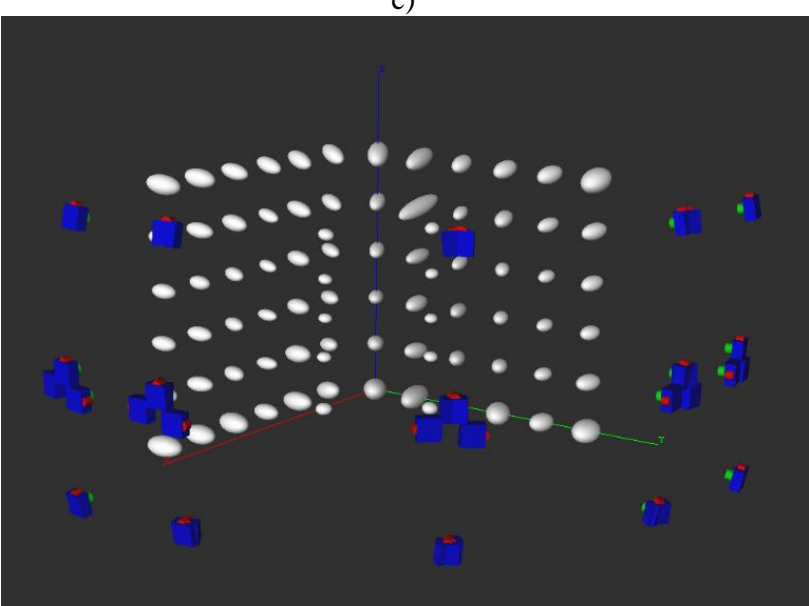

Figure 3. Calibration testfield (a), example of planar target (b) and typical camera network (c) for the geometric calibration of the MAIA multispectral camera. 


\subsection{Main characteristics}

A global shutter technology is implemented: the pixels of all sensors start collecting charge simultaneously, allowing the images to be acquired in "one shot" for synchronized multiband measurements. This way, even at high acquisition speed, the negative effects usually produced by a rolling shutter, e.g. the socalled wobble or jello effect, are avoided. Exposure time can be as fast as $1 / 5000 \mathrm{sec}$.

Acquisition settings, such as the exposure time and acquisition frame rate, can be finely adjusted through the user interface to best match the specific application conditions. The images are stored in an internal solid state hard disk (SSD), which a memory capacity of more than 10,000 images. The images are saved in a proprietary RAW format, in 8bit, 10bit or 12bit. Through the proprietary software application, the user has access to the camera to (i) configure the parameters, (ii) visualise a live view preview in real-time during the acquisition and (iii) capture and store the selected images to the internal storage. For these purposes, various interfaces are available: the control keyboard,
NTSC/PAL video output, a web panel, and two inputs for remote controllers. Remote control access is available through either a high-speed GigaEthernet connection or Wifi connection to a PC, tablet or smartphone, useful when used in the field.

\subsection{Additional features}

The MAIA camera can be connected with other sensors in order to embed additional information with the acquired images, such as:

- an external GNSS receiver to geo-tag the images;

- a radio transmitter to send images to the user to allow for realtime check;

- a link to a remote controller to manually modify some parameters during a flight;

- a gimbal linked to the inertial sensor inside the camera to keep constant or adapt the orientation during a flight;

- other devices that can provide or need a precise synchronisation signal at the same moment of image exposure.

\begin{tabular}{|c|c|c|c|c|c|c|c|c|c|}
\hline \multicolumn{10}{|c|}{ MAIA } \\
\hline & b1 & $b 2$ & b3 & $b 4$ & b5 & b6 & b7 & $b 8$ & b9 \\
\hline $\begin{array}{c}\text { Principal } \\
\text { distance c }[\mathrm{mm}] \\
\end{array}$ & 7.592 & 7.490 & 7.474 & 7.509 & 7.641 & 7.469 & 7.619 & 7.570 & 7.494 \\
\hline$\sigma_{c}[\mathrm{~mm}]$ & $.1 \mathrm{e}-004$ & $8.5 \mathrm{e}-004$ & $4.7 \mathrm{e}-004$ & $3.8 \mathrm{e}-004$ & $4.2 \mathrm{e}-004$ & $5.0 \mathrm{e}-004$ & $5.5 \mathrm{e}-004$ & $5.4 \mathrm{e}-004$ & $5.3 e-004$ \\
\hline $\begin{array}{c}\text { Principal point } \\
\text { ppx [mm] }\end{array}$ & -0.081 & -0.047 & -0.020 & -0.119 & -0.117 & 0.017 & -0.080 & -0.066 & -0.094 \\
\hline$\sigma_{p p x}[\mathrm{~mm}]$ & $2 \mathrm{e}-004$ & 0.002 & $8.3 \mathrm{e}-004$ & $6.6 \mathrm{e}-004$ & $7.4 \mathrm{e}-004$ & $8.4 \mathrm{e}-004$ & $9.2 \mathrm{e}-004$ & $9.1 \mathrm{e}-004$ & $9.0 \mathrm{e}-004$ \\
\hline $\begin{array}{c}\text { Principal point } \\
\text { ppy }[\mathrm{mm}]\end{array}$ & -0.0490 & 0.003 & 0.058 & 0.041 & 0.010 & 0.036 & 0.096 & 0.034 & 0.081 \\
\hline$\sigma_{\text {ppy }}[\mathrm{mm}]$ & 7.6e-004 & 0.001 & $6.8 \mathrm{e}-004$ & $5.5 \mathrm{e}-004$ & $6.2 \mathrm{e}-004$ & $7.3 \mathrm{e}-004$ & $7.8 \mathrm{e}-004$ & $7.8 \mathrm{e}-004$ & $7.7 \mathrm{e}-004$ \\
\hline $\mathbf{k} \mathbf{1}\left[\mathrm{mm}^{-2}\right]$ & $1.8 \mathrm{e}-003$ & $1.9 \mathrm{e}-003$ & $1.9 \mathrm{e}-003$ & $2.0 \mathrm{e}-003$ & $2.0 \mathrm{e}-003$ & $2.0 \mathrm{e}-003$ & $1.9 \mathrm{e}-003$ & $1.9 \mathrm{e}-003$ & $1.9 \mathrm{e}-003$ \\
\hline$\sigma_{\mathbf{k} \mathbf{1}}\left[\mathrm{mm}^{-2}\right]$ & $1.2 \mathrm{e}-005$ & $2.0 \mathrm{e}-005$ & $1.1 \mathrm{e}-005$ & $9.0 \mathrm{e}-006$ & $9.3 e-006$ & $1.1 \mathrm{e}-006$ & $1.2 \mathrm{e}-005$ & $1.2 \mathrm{e}-005$ & $1.2 \mathrm{e}-005$ \\
\hline $\mathbf{k} \mathbf{2}\left[\mathrm{mm}^{-4}\right]$ & $-2.0 \mathrm{e}-005$ & $-2.3 e-005$ & $2.3 \mathrm{e}-005$ & $-1.7 e-005$ & $-1.3 e-005$ & $-2.1 \mathrm{e}-005$ & $-1.7 e-005$ & $-1.8 \mathrm{e}-005$ & $-1.4 \mathrm{e}-005$ \\
\hline$\sigma_{\mathrm{k} 2}\left[\mathrm{~mm}^{-4}\right]$ & $1.4 \mathrm{e}-006$ & $2.4 \mathrm{e}-006$ & $1.3 \mathrm{e}-006$ & $1.1 \mathrm{e}-006$ & $1.1 \mathrm{e}-006$ & $1.3 \mathrm{e}-006$ & $1.4 \mathrm{e}-006$ & $1.4 \mathrm{e}-006$ & $1.4 \mathrm{e}-006$ \\
\hline $\mathbf{P 1}\left[\mathrm{mm}^{-1}\right]$ & $1.8 \mathrm{e}-005$ & $6.8 \mathrm{e}-005$ & $8.8 \mathrm{e}-005$ & $4.1 \mathrm{e}-005$ & $1.7 \mathrm{e}-005$ & $-2.3 e-004$ & $-2.2 \mathrm{e}-004$ & $5.1 \mathrm{e}-005$ & $2.9 \mathrm{e}-004$ \\
\hline$\sigma_{P 1}\left[\mathrm{~mm}^{-1}\right]$ & $4.6 \mathrm{e}-006$ & $8.2 \mathrm{e}-006$ & $4.6 \mathrm{e}-006$ & $3.4 \mathrm{e}-006$ & $3.6 \mathrm{e}-006$ & $4.4 \mathrm{e}-006$ & $4.6 \mathrm{e}-006$ & $4.7 \mathrm{e}-006$ & $4.7 \mathrm{e}-006$ \\
\hline $\mathbf{P} 2\left[\mathrm{~mm}^{-1}\right]$ & $2.1 \mathrm{e}-004$ & $2.8 \mathrm{e}-005$ & $-1.9 \mathrm{e}-004$ & $4.0 \mathrm{e}-006$ & $1.5 \mathrm{e}-004$ & $4.5 \mathrm{e}-005$ & $-1.5 e-004$ & $2.8 \mathrm{e}-004$ & $-1.6 e-004$ \\
\hline$\sigma_{\mathbf{P} 2}\left[\mathrm{~mm}^{-1}\right]$ & $3.9 \mathrm{e}-006$ & $6.9 \mathrm{e}-006$ & $3.6 \mathrm{e}-006$ & $2.9 \mathrm{e}-006$ & $3.0 \mathrm{e}-006$ & $3.8 \mathrm{e}-006$ & $4.0 \mathrm{e}-006$ & $4.0 \mathrm{e}-006$ & $4.0 \mathrm{e}-006$ \\
\hline \multicolumn{10}{|c|}{ MAIA/S2 } \\
\hline & $b 1$ & $b 2$ & b3 & $b 4$ & b5 & $b 6$ & b7 & $b 8$ & $b^{9}$ \\
\hline $\begin{array}{c}\text { Principal } \\
\text { distance } \mathbf{c}[\mathrm{mm}]\end{array}$ & 7.512 & 7.527 & 7.578 & 7.550 & 7.522 & 7.525 & 7.556 & 7.576 & 7.666 \\
\hline$\sigma_{c}[\mathrm{~mm}]$ & $6.3 \mathrm{e}-004$ & $4.4 \mathrm{e}-004$ & $5.6 \mathrm{e}-004$ & $5.4 \mathrm{e}-004$ & $5.3 \mathrm{e}-004$ & $5.4 \mathrm{e}-004$ & $8.9 \mathrm{e}-004$ & $5.7 \mathrm{e}-004$ & $6.1 \mathrm{e}-004$ \\
\hline $\begin{array}{l}\text { Principal point } \\
\text { ppx }[\mathrm{mm}]\end{array}$ & -0.157 & -0.056 & -0.019 & -0.111 & -0.066 & -0.010 & -0.0188 & -0.082 & 0.041 \\
\hline$\sigma_{p p x}[\mathrm{~mm}]$ & 0.001 & $7.3 e-004$ & $9.5 \mathrm{e}-004$ & $8.4 \mathrm{e}-004$ & $8.3 \mathrm{e}-004$ & $8.6 \mathrm{e}-004$ & 0.001 & $9.1 \mathrm{e}-004$ & $9.6 \mathrm{e}-004$ \\
\hline $\begin{array}{c}\text { Principal point } \\
\text { ppy }[\mathrm{mm}]\end{array}$ & 0.007 & -0.013 & -0.029 & 0.029 & 0.081 & 0.052 & 0.0136 & 0.027 & -0.001 \\
\hline$\sigma_{p p y}[\mathrm{~mm}]$ & $8.4 \mathrm{e}-004$ & $6.2 \mathrm{e}-004$ & $8.2 \mathrm{e}-004$ & 7.1e-004 & $7.0 \mathrm{e}-004$ & 7.2e-004 & 0.001 & $7.8 \mathrm{e}-004$ & $8.2 \mathrm{e}-004$ \\
\hline $\mathbf{k} \mathbf{1}\left[\mathrm{mm}^{-2}\right]$ & $-2.0 \mathrm{e}-003$ & $2.1 \mathrm{e}-003$ & $2.1 \mathrm{e}-003$ & $2.1 \mathrm{e}-003$ & $2.1 \mathrm{e}-003$ & $2.2 \mathrm{e}-003$ & $2.1 \mathrm{e}-003$ & $2.0 \mathrm{e}-003$ & $2.0 \mathrm{e}-003$ \\
\hline$\sigma_{\mathrm{k} \mathbf{1}}\left[\mathrm{mm}^{-2}\right]$ & $1.5 \mathrm{e}-005$ & $9.8 \mathrm{e}-006$ & $1.2 \mathrm{e}-005$ & $1.2 \mathrm{e}-005$ & $1.2 \mathrm{e}-005$ & $1.2 \mathrm{e}-005$ & $2.0 \mathrm{e}-005$ & $1.2 \mathrm{e}-005$ & $1.2 \mathrm{e}-005$ \\
\hline $\mathbf{k} \mathbf{2}\left[\mathrm{mm}^{-4}\right]$ & $3.5 \mathrm{e}-005$ & $-3.0 \mathrm{e}-005$ & $-2.5 e-005$ & $-3.0 \mathrm{e}-005$ & $-2.7 e-005$ & $-3.1 e-005$ & $-2.6 e-005$ & $-2.3 e-005$ & $-2.4 \mathrm{e}-005$ \\
\hline$\sigma_{\mathrm{k} 2}\left[\mathrm{~mm}^{-4}\right]$ & $1.7 \mathrm{e}-006$ & $1.2 \mathrm{e}-006$ & $1.5 \mathrm{e}-006$ & $1.4 \mathrm{e}-006$ & $1.4 \mathrm{e}-006$ & $1.4 \mathrm{e}-006$ & $2.4 \mathrm{e}-006$ & $1.5 \mathrm{e}-006$ & $1.5 \mathrm{e}-006$ \\
\hline $\mathbf{P 1}\left[\mathrm{mm}^{-1}\right]$ & $9.3 \mathrm{e}-005$ & $-4.5 e-005$ & $-1.0 \mathrm{e}-004$ & $-3.0 \mathrm{e}-004$ & $-2.2 \mathrm{e}-004$ & $9.3 \mathrm{e}-005$ & $-3.0 \mathrm{e}-004$ & \begin{tabular}{|l|}
$-4.1 e-005$ \\
\end{tabular} & $-1.7 \mathrm{e}-004$ \\
\hline$\sigma_{\mathbf{P} 1}\left[\mathrm{~mm}^{-1}\right]$ & $5.3 e-006$ & $3.6 \mathrm{e}-006$ & $4.6 \mathrm{e}-006$ & $4.2 \mathrm{e}-006$ & $4.2 \mathrm{e}-006$ & $4.3 \mathrm{e}-006$ & $7.1 \mathrm{e}-006$ & $4.5 \mathrm{e}-006$ & $4.7 \mathrm{e}-006$ \\
\hline $\mathbf{P 2}\left[\mathrm{mm}^{-1}\right]$ & -2.7 e- 004 & $3.7 \mathrm{e}-006$ & $2.1 \mathrm{e}-004$ & $-4.7 e-005$ & $7.8 \mathrm{e}-005$ & $1.2 \mathrm{e}-004$ & $1.2 \mathrm{e}-004$ & $8.2 \mathrm{e}-005$ & $-7.7 e-005$ \\
\hline$\sigma_{\mathbf{P} 2}\left[\mathrm{~mm}^{-1}\right]$ & $4.5 \mathrm{e}-006$ & $3.1 \mathrm{e}-006$ & $4.0 \mathrm{e}-006$ & $3.6 \mathrm{e}-006$ & $3.6 \mathrm{e}-006$ & $3.7 \mathrm{e}-006$ & $6.1 \mathrm{e}-006$ & $3.9 \mathrm{e}-006$ & $4.1 \mathrm{e}-006$ \\
\hline
\end{tabular}

Table 2. Results of self-calibrating bundle adjustment for two MAIA cameras. 


\section{GEOMETRIC CALIBRATION}

Geometric calibration of optical systems (Remondino and Fraser, 2006), i.e. the knowledge of image formation geometry through the computation of the interior orientation and lens distortion parameters, is crucial for the achievement of accurate measurements. Due to mechanical tolerances, typical of manufacturing processes, and physical trends in the calibration parameters as the light wavelengths change (Robson et al., 2014), the geometric calibration plays, along with the radiometric calibration, a fundamental role to fully exploit the accuracy potential of multispectral system.

In the MAIA camera system, each mono-chromatic sensor is equipped with a fixed focus lens, whose focusing distance is set in laboratory and not adjustable by the user. A calibration certificate is provided for each sensor with a two-fold aim: (i) the calibrated interior orientation parameters can be used during photogrammetric processing; (ii) the calibration parameters are adopted to remove geometric distortion when co-registering the multi-band images and producing a combined multi-layer multichannel image.

\subsection{The testfield for the MAIA geometrical calibration and camera calibration acquisition protocol}

For the geometrical characterization of the nine MAIA sensors, an ad-hoc testfield has been designed and arranged in a dedicated facility at 3DOM-FBK laboratory (Figure 3a). The test field features a volumetric shape with two orthogonal planes obtained by fixing 72 target plates over a corner of the laboratory room. 10 additional target plate are fixed to two vertical rigid poles to enhance depth variation within the calibration volume. The overall size of the test field is $2.4 \times 2.4 \times 2 \mathrm{~m}^{3}$.

Each target plate (Figure $3 b$ ) features a central circular coded target with a diameter of $35 \mathrm{~mm}$ whose center is realized to lie on the barycenter of the rectangle defined by four coded targets of smaller diameter $(5 \mathrm{~mm})$. The center of the $35 \mathrm{~mm}$ target is signalized by a cross that can be also measured with a total station. The circular targets within a single plate are printed in different size to be optimally imaged on pictures characterized by different image scale, practically eliminating the effect of target eccentricity (Luhman, 2014). In particular, the $35 \mathrm{~mm}$ target is designed to be measured by the MAIA sensors at a distance of about $4 \mathrm{~m}$. The $5 \mathrm{~mm}$ targets are optimal to be imaged by a higher resolution photogrammetric system to be used as reference to assess the accuracy potential of the multi-spectral MAIA camera. Two $1.1 \mathrm{~m}$ long certified length bars from Brunson are also fitted within the calibration volume, and used to scale and compute length measurement errors (VDI/VDE 2634, 2002). A tungsten halogen source, emitting light in all the wavelength intervals acquired by the MAIA sensors, is used to guarantee the proper illumination during the image acquisition step.

A strict and repeatable acquisition protocol is followed, entailing some 40 camera positions (Figure 3c) at three different heights with roll diversity, guarantying an average intersection angle of about 75 degrees. The acquisition distance is $4 \mathrm{~m}$, providing a ground sample distance (GSD) better than $2 \mathrm{~mm}$.

\subsection{The accuracy potential of MAIA}

To assess the accuracy potential of the MAIA cameras, the test field is measured also with a professional digital single lens reflex (DSLR), a Nikon D750 equipped with a fixed lens (AF Nikkor $28 \mathrm{~mm} \mathrm{f} / 2.8 \mathrm{D}$ ). The obtained average GSD is approximatively $0.5 \mathrm{~mm}$, and the expected spatial accuracy of the reference coordinates about $0.1 \mathrm{~mm}$ (considering temperature and humidity variations as well as mechanical stability of the test field).

\begin{tabular}{|c|c|c|c|c|c|c|c|c|c|c|}
\hline \multicolumn{2}{|c|}{ MAIA } & \multicolumn{1}{c|}{$\boldsymbol{b}$} \\
\hline $\begin{array}{c}\text { RMS image residuals } \\
\text { [pixel] }\end{array}$ & 0.064 & 0.116 & 0.065 & 0.052 & 0.057 & 0.660 & 0.071 & 0.070 & 0.069 \\
\hline $\begin{array}{c}\text { Maximum image } \\
\text { residuals [pixel] }\end{array}$ & 0.153 & 0.358 & 0.552 & 0.600 & 0.748 & 0.366 & 0.388 & 0.385 & 0.548 \\
\hline $\begin{array}{c}\text { RMS point vector } \\
\text { length [mm] }\end{array}$ & 0.085 & 0.149 & 0.096 & 0.065 & 0.070 & 0.124 & 0.106 & 0.0975 & 0.090 \\
\hline $\begin{array}{c}\text { Maximum point } \\
\text { vector length [mm] }\end{array}$ & 0.158 & 0.311 & 0.448 & 0.124 & 0.136 & 0.620 & 0.444 & 0.351 & 0.192 \\
\hline $\begin{array}{c}\text { RMSE (wrt reference } \\
\text { data) [mm] }\end{array}$ & 0.300 & 0.376 & 0.286 & 0.267 & 0.267 & 0.337 & 0.270 & 0.283 & 0.285 \\
\hline $\begin{array}{c}\text { RM } \\
\text { RMS image residuals } \\
\text { [pixel] }\end{array}$ & 0.081 & 0.056 & 0.072 & 0.069 & 0.070 & 0.069 & 0.114 & 0.071 & 0.073 \\
\hline $\begin{array}{c}\text { Maximum image } \\
\text { residuals [pixel] }\end{array}$ & 0.339 & 0.395 & 0.337 & 0.401 & 0.441 & 0.492 & 0.471 & 0.453 & 0.388 \\
\hline $\begin{array}{c}\text { RMS point vector } \\
\text { length [mm] }\end{array}$ & 0.100 & 0.069 & 0.088 & 0.089 & 0.106 & 0.086 & 0.142 & 0.091 & 0.102 \\
\hline $\begin{array}{c}\text { Maximum point } \\
\text { vector length [mm] }\end{array}$ & 0.198 & 0.134 & 0.198 & 0.257 & 0.538 & 0.182 & 0.296 & 0.184 & 0.351 \\
\hline $\begin{array}{c}\text { RMSE (wrt reference } \\
\text { data) [mm] }\end{array}$ & 0.339 & 0.318 & 0.309 & 0.320 & 0.327 & 0.327 & 0.426 & 0.330 & 0.325 \\
\hline
\end{tabular}

Table 3. Internal and external assessment of the self-calibrating bundle adjustment for two MAIA cameras. 
a)
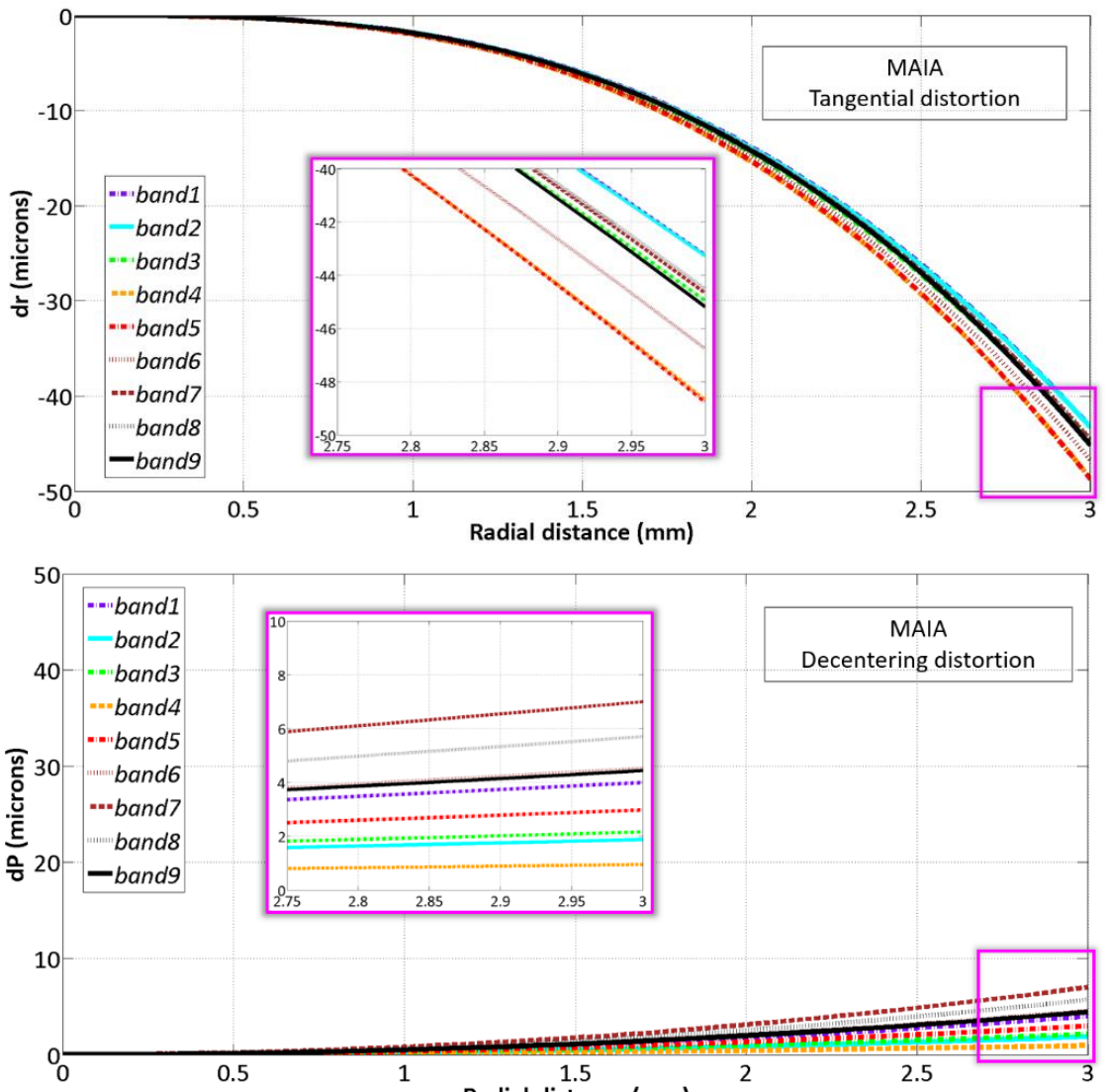

b)

Radial distance $(\mathrm{mm})$

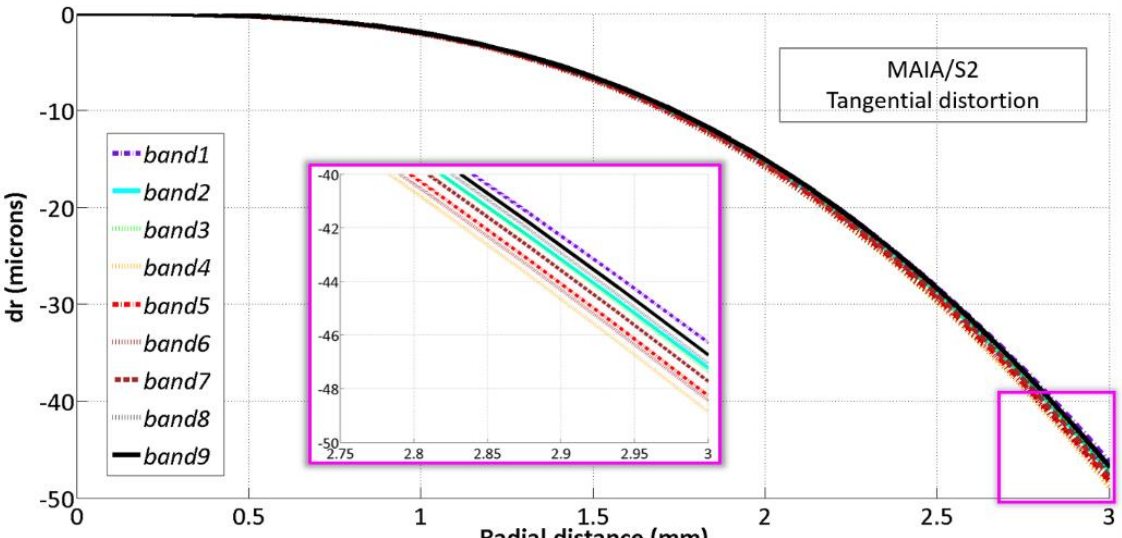

c)

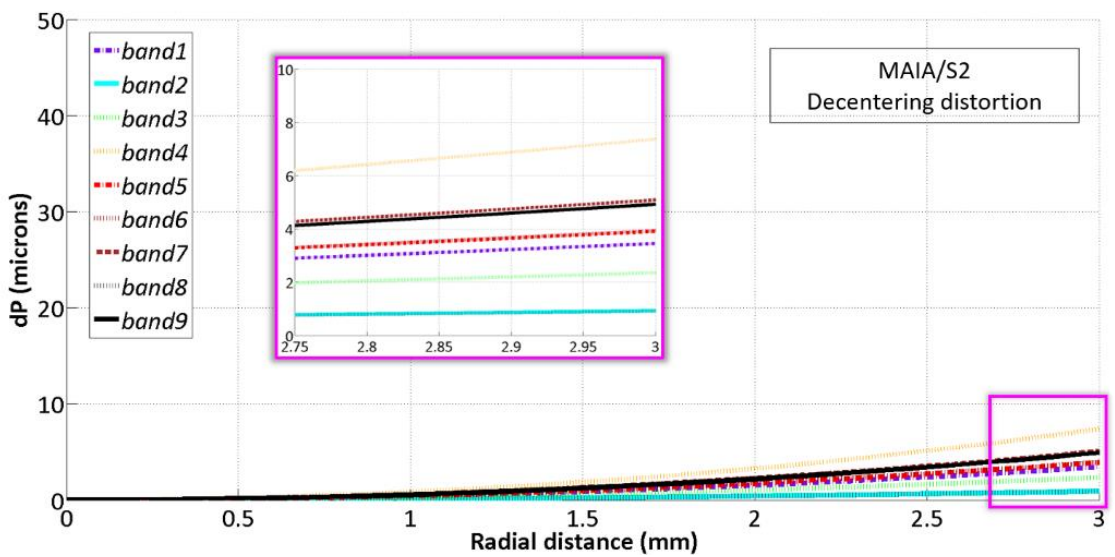

Figure 4. Typical radial (a, c) and decentring (b, d) distortion curves of the nine MAIA (a, b) and MAIA/S2 (c,d) spectral bands. 
Figure 4 shows typical radial (a-b) and decentring distortion curves (c-d) for the different MAIA spectral bands. Table 2 summarises the values and standard deviations of camera calibration parameters for the same sensors, where $(\mathrm{k} 1, \mathrm{k} 2)$ and $(\mathrm{P} 1, \mathrm{P} 2)$ are the coefficients of the radial and decentring distortions respectively. The radial distortion parameter $\mathrm{k} 3$, as well as the affinity and share factors, are not computed since their values are found to be not significant. It is worth noting that the variation of principal distance values is due to a combination of the different focusing setting for each channel, and the acquired light wavelengths. Moreover, the observed difference in the distortion curves is caused by the change of the refractive indices of the lens elements, being them a function of the wavelength (Ray, 2002).

Table 3 reports the internal and external assessment of the selfcalibrating bundle adjustments for the two MAIA sensors. The internal assessment is evaluated in the image space through the root mean square (RMS) and maximum values of image observation residuals, while for the object space the theoretical precision of 3D object coordinates is computed. The external assessment is performed by calculating the RMS error (RMSE) of the differences between the 3D coordinates of the targets measured with the MAIA cameras and the reference DSLR Nikon D750.

\section{RADIOMETRIC ADJUSTMENT}

Radiometric calibration is the process through which the digital numbers (DNs) recorded by the pixels on the sensor are converted into units of radiance (Hruska et al., 2012).

The raw at-sensor data are affected by different effects, which include sensor characteristics, surface and topographic conditions, atmospheric effects, etc. (Kelcey and Lucieer, 2012). In order to retrieve the correct incoming radiance values, the radiometric adjustment entails two sequential steps: (i) removal of optical system effects from the measurements (Section 4.1) and (ii) elimination of the environmental conditions effects (Section 4.2).

\subsection{Radial radiometric or flat-field correction: vignetting}

Natural vignetting, also known as light falloff, is the effect of decrease in illumination radially from the center of the image toward the borders (Ray, 2002). The reduction follows the socalled $\cos ^{4} \vartheta$ law of illumination, where $\vartheta$ is the angle of a ray with respect to the optical axis. The employed method for the vignetting correction relies upon the the generation of a per-pixel correction factor look-up-table (LUT). An example of vignettingfree image is shown in Figure $5 b$.

\subsection{Radiometric correction}

The radiometric correction is used in post-processing to correct for the component of irradiance light (normally the sun) and obtain the radiance of the elements (plants, terrain, etc.) that compose the scene.

Radiometric calibration is usually performed in laboratory or inflight (Del Pozo et al., 2014; Dinguirard and Slater, 1999; Markelin, 2013; McGlone, 2013). The latter method, also known as vicarious calibration, requires in-situ measurements, using reflectance targets, solar photometers and radiative transfer codes.

Three different in-flight radiometric calibration approaches are implemented via the MAIA proprietary software application: (i) automatic empirical correction; (ii) estimation of the correction using a radiometrically calibrated target; (iii) adoption of a rigorous correction method based on the use of an ad-hoc developed Irradiance Light Sensor (ILS, patent pending - Figure $5 c)$.

The automatic empirical correction takes into account several parameters (quantum efficiency of the sensor, transmittance value, bandwidth, and exposure time measured in milliseconds) to correct the DN values for all the bands. The quantum efficiency coefficient is based either on the efficiency curve of the sun or on the efficiency curve resulting from a flat light source.

When a calibrated target is employed, usually white painted made of barium sulfate (Schutt et al., 1974), its calibrated reflectance $\mathrm{Rt}_{\mathrm{i}}$ are known in all the $\mathrm{B}_{\mathrm{i}}$ spectral bands. Being $\mathrm{Pt}_{\mathrm{i}}$ the luminous intensity value of the same target measured by the $B_{i}$ bands of the camera, the corrected reflectance value of the scene DN' (always) is provided by (1) for each spectral band:

$$
D N^{\prime}{ }_{i}=\frac{R t_{i}}{P t_{i}} \cdot D N_{i}
$$

Figure 6 shows a MAIA/S2 image in the violet band corrected through a reference white target.

b)
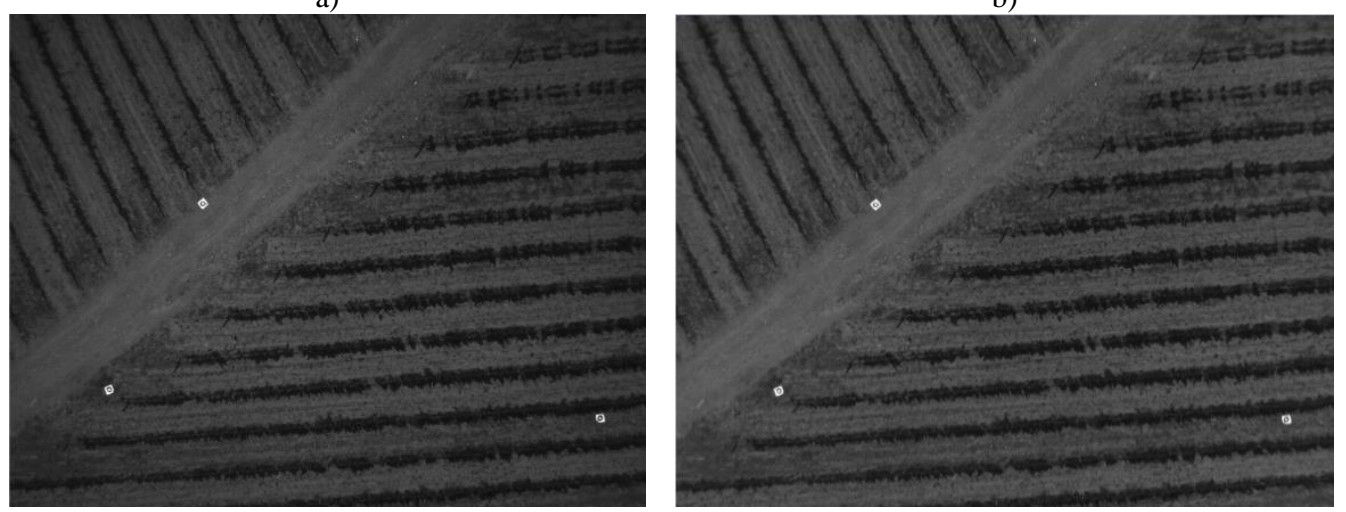

c)

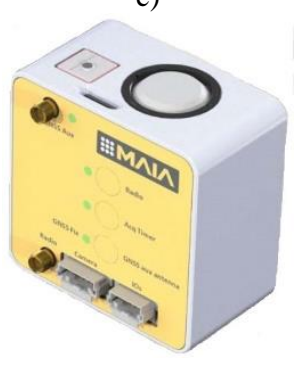

Figure 5: A monochromatic image in band 1 (Violet) of MAIA/S2 before (a) and after (b) the vignetting correction (b). The designed MAIA Irradiance Light Sensor - ILS (c). 

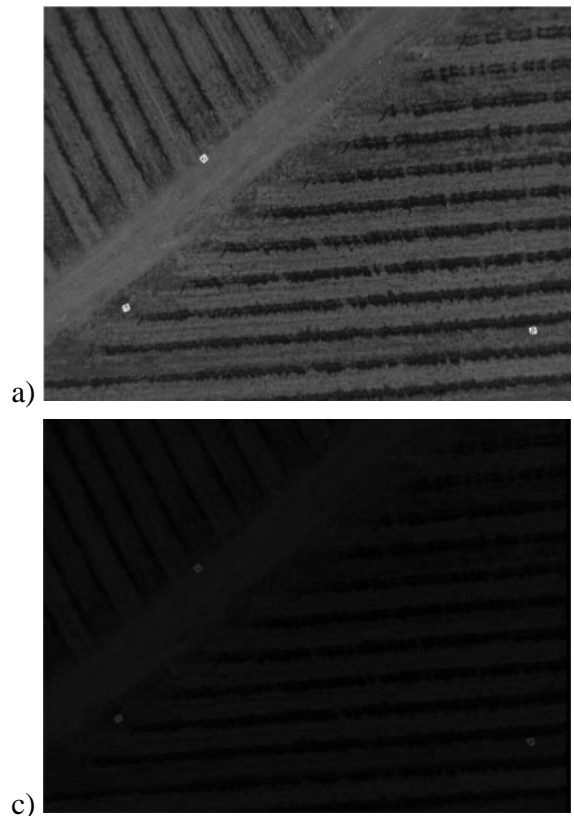

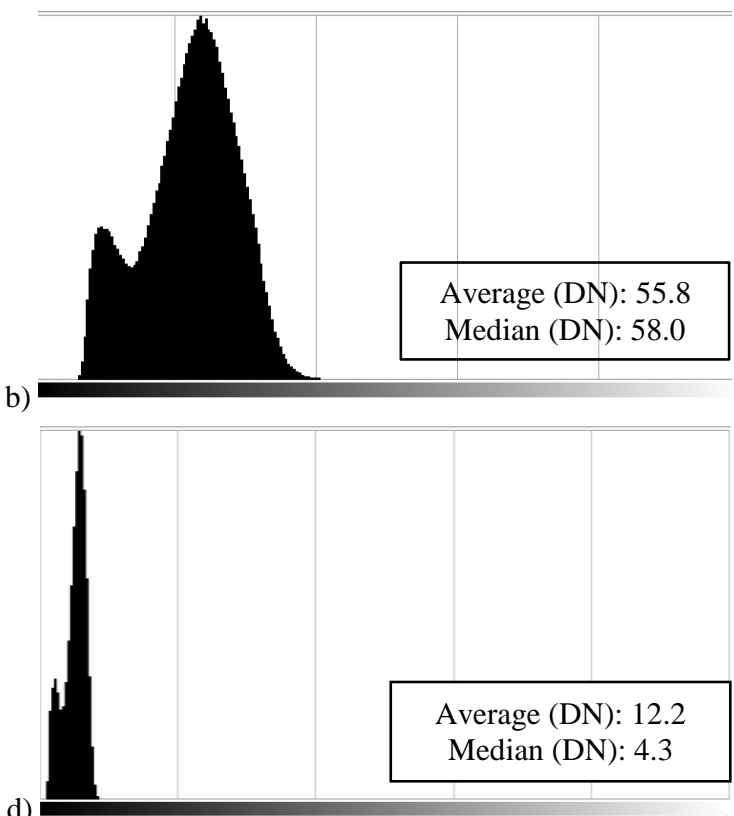
Figure 6: Monochromatic image in band 1 (Violet) of MAIA/S2 (a) with the corresponding histogram (b) before radiometric
correction; the same image (c) and corresponding histogram (d) after applying the radiometric correction for the irradiance light using a white target.

The use of a calibrated target may provide satisfactory results, although several issues may arise. In particular, if the target is imaged in varying lighting conditions (e.g., sunny or cloudy) that differ from other areas of the scene of interest, the calculated correction cannot be considered valid through the entire dataset.

The use of the ILS may improve the radiometric correction results. The ILS measures the radiation from the light source (e.g. the sun), providing reference values of the incident radiation for all the bands. This approach assumes that the radiation measured by the ILS is the same that irradiates the scene of interest. If this hypothesis is verified, the corrected reflectance value of the scene $\mathrm{DN}^{\prime}$ for each $\mathrm{B}_{\mathrm{i}}$ spectral band is computed according to (2):

$$
D N^{\prime}{ }_{i}=\frac{1}{I L S_{i}} \cdot D N_{i}
$$

being ILS $\mathrm{S}_{\mathrm{i}}$ the value of the light intensity detected by the ILS for each $B_{i}$ spectral band.

The MAIA ILS is equipped with the same CMOS sensor of the MAIA cameras and it is provided with the two set of bandpass filters, either the WorlView-2 or Sentinel2 versions. The measured ILS $S_{i}$ are synchronous with each image acquired by the MAIA camera.

\section{CONCLUSIONS}

The paper presented the main technical features of the MAIA multispectral camera (http://www.spectralcam.com) together with methods currently implemented for its geometric and radiometric characterization. These procedures are necessary for the special tasks the camera is designed for, i.e. diagnostic, monitoring and remote sensing for different application fields such as precision farming and environmental monitoring where reliable and accurate information is mandatory. State of the art methods, inspired by international standards, are used for determining the geometric calibration parameters of each sensor and their accuracy potential in a controlled environment at FBK facilities. The examples reported for the two specific MAIA and MAIA/S2 units, show sub millimetric accuracy within the testfield volume for all bands, corresponding to a relative accuracy with respect to its diagonal (ca 3.8m) of about 1:11,000. Similar results have been observed with all the other units and will be presented in a future work. For the two example provided, the radial distortion graphs show that the used lenses are very well corrected with the maximum distortion below 15 pixels and each radial curve differing from the others for less than two pixels. These values prove the consistency between the used lenses, the same for each imaging sensor. Main differences observed in the principal distance are due to physical reasons (wavelength dependant refraction coefficients), which require a different focusing for each lens. Principal point variation between the bands is below 30 pixels and within expected centering of the optical axis of small format sensors. In a future work, the relative orientation between the cameras will be analysed in order to be utilized in the photogrammetric processing.

Radiometric calibration is mandatory if quantitative indexes need to be computed from the bands available with the MAIA camera (in both versions, WorlView-2 and Sentinel2). Three types of radiometric corrections that use automatic as well as specifically built reference targets or an ad-hoc ILS sensor have been presented.

\section{REFERENCES}

Adam, E., Mutanga, O. and Rugege, D., 2010. Multispectral and hyperspectral remote sensing for identification and mapping of 
wetland vegetation: a review. Wetlands Ecology and Management, 18(3), pp.281-296.

Ahamed, T., Tian, L., Zhang, Y. and Ting, K.C., 2011. A review of remote sensing methods for biomass feedstock production. Biomass and Bioenergy, 35(7), pp.2455-2469.

Berni, J.A., Zarco-Tejada, P.J., Suárez, L. and Fereres, E., 2009. Thermal and narrowband multispectral remote sensing for vegetation monitoring from an unmanned aerial vehicle. IEEE Transactions on Geoscience and Remote Sensing, 47(3), pp.722738.

Candiago, S., Remondino, F., De Giglio, M., Dubbini, M. and Gattelli, M., 2015. Evaluating multispectral images and vegetation indices for precision farming applications from UAV images. Remote Sensing, 7(4), pp.4026-4047.

Del Pozo, S., Rodríguez-Gonzálvez, P., Hernández-López, D. and Felipe-García, B., 2014. Vicarious radiometric calibration of a multispectral camera on board an unmanned aerial system. Remote Sensing, 6(3), pp. 1918-1937.

DigitalGlobe, 2009. WorldView-2 Data sheet. https://dg-cmsuploads-

production.s3.amazonaws.com/uploads/document/file/98/World View2-DS-WV2-rev2.pdf

Dinguirard, M. and Slater, P.N., 1999. Calibration of spacemultispectral imaging sensors: A review. Remote Sensing of Environment, 68(3), pp.194-205.

Dubbini, M., Pezzuolo, A., De Giglio, M., Gattelli, M., Curzio, L., Covi, D., Yezekyan, T. and Marinello, F., 2017. Last generation instrument for agriculture multispectral data collection. CIGR Journal, 19(1): 87-93. ISSN: 1682-1130.

ESA, European Space Agency, 2012. Sentinel-2. ESA's Optical High-Resolution Mission for GMES Operational Services. http://esamultimedia.esa.int/multimedia/publications/SP1322_2/

Hruska, R., Mitchell, J., Anderson, M. and Glenn, N.F., 2012. Radiometric and geometric analysis of hyperspectral imagery acquired from an unmanned aerial vehicle. Remote Sensing, 4(9), pp.2736-2752.

Kelcey, J. and Lucieer, A., 2012. Sensor correction of a 6-band multispectral imaging sensor for UAV remote sensing. Remote Sensing, 4(5), pp.1462-1493.

Markelin, L., 2013. Radiometric calibration, validation and correction of multispectral photogrammetric imagery. Finnish Geodetic Institute.

Leifer, I., Lehr, W.J., Simecek-Beatty, D., Bradley, E., Clark, R., Dennison, P., Hu, Y., Matheson, S., Jones, C.E., Holt, B. and Reif, M., 2012. State of the art satellite and airborne marine oil spill remote sensing: Application to the BP Deepwater Horizon oil spill. Remote Sensing of Environment, 124, pp.185-209.

Liang, H., 2012. Advances in multispectral and hyperspectral imaging for archaeology and art conservation. Applied Physics A, 106(2), pp.309-323.

Luhmann, T., 2014. Eccentricity in images of circular and spherical targets and its impact on spatial intersection. The Photogrammetric Record, 29(148), pp.417-433.
McGlone, J.C. ed., 2013. Manual of photogrammetry. American Soc. for Photogrammetry and Remote Sensing.

Mulla, D.J., 2013. Twenty five years of remote sensing in precision agriculture: Key advances and remaining knowledge gaps. Biosystems engineering, 114(4), pp.358-371.

Panagou, E.Z., Papadopoulou, O., Carstensen, J.M. and Nychas, G.J.E., 2014. Potential of multispectral imaging technology for rapid and non-destructive determination of the microbiological quality of beef filets during aerobic storage. International journal of food microbiology, 174, pp.1-11.

Ray, S.F., 2002. Applied photographic optics: Lenses and optical systems for photography, film, video, electronic and digital imaging. Focal Press.

Remondino, F., Fraser, C., 2006. Digital camera calibration methods: considerations and comparisons. In: International Archives of Photogrammetry, Remote Sensing and Spatial Information Sciences, 36(5), pp. 266-272.

Remondino, F., Rizzi, A., Barazzetti, L., Scaioni, M., Fassi, F., Brumana, R., Pelagotti, A., 2011. Review of geometric and radiometric analyses of paintings. The Photogrammetric Record, 26(136), pp. 439-461

Robson, S., MacDonald, L., Kyle, S.A. and Shortis, M.R., 2014. Multispectral calibration to enhance the metrology performance of C-mount camera systems. In: International Archives of Photogrammetry, Remote Sensing and Spatial Information Sciences, 40(5), p.517.

Schutt, J.B., Arens, J.F., Shai, C.M. and Stromberg, E., 1974. Highly reflecting stable white paint for the detection of ultraviolet and visible radiations. Applied optics, 13(10), pp. 2218-2221.

Shaw, G.A. and Burke, H.K., 2003. Spectral imaging for remote sensing. Lincoln Laboratory Journal, 14(1), pp.3-28.

VDI/VDE 2634, 2002. Guideline 2634 part 1, Optical 3D measuring systems - Imaging systems with point-by-point probing.

Zang, W., Lin, J., Wang, Y. and Tao, H., 2012, June. Investigating small-scale water pollution with UAV remote sensing technology. In: World Automation Congress (WAC), 2012 (pp. 1-4). IEEE. 